\title{
Public Health Bioethics
}

\author{
Miguel Kottow \\ Escuela de Salud Pública Universidad de Chile, \\ Chile
}

\section{Introduction}

The approach of bioethics to the theory and practice of public health is recent and tentative, leading to a highly controversial field of inquiry, and equally polemic normative proposals. In spite of its enormous academic popularity, bioethics has been criticized and faulted for excessive theoretical zeal, and a penchant for highly specific issues that ignore the problems of health and disease at a more global level. Bioethics frequently indulges in holistic ethical language that appears vacuous and unrealistic, unable to come up with practical suggestions for everyday decision-making.

Applied ethics is concerned with ethical questions and dilemmas arising in social practices; consequently, bioethics encompasses ethical reflection across the whole gamut of biomedical practices including clinical, public health, and research aspects. The bioethical understanding of such a complex social reality as public health requires a working knowledge of the historical development and actual scope of public health, a daunting task that needs to be at least cursorily approached, especially since mapping the agenda of public health will lead to address such disparate disciplines as ethics and axiology -the study of values-, cultural perspectives, sociological, epistemological and general philosophical questions. Defining and refining concepts involves values, thus showing $a b$ initio that [bio]ethics is inextricably interwoven in the social practice of public health. An yet, there is no widespread agreement whether the moral aspects of public health should be understood as professional ethics or, rather, as a branch of the recently developing discipline of bioethics.

To introduce the theory and practice of ethics into public health would be extemporaneous if strictly based on traditional views derived from deontology, utilitarianism or virtue ethics, all of them concerned with essential and absolute concepts like Right or Wrong, Good or Evil, and Virtue versus Sin. Aristotele, Kant and Mill are all at the foundations of ethical thought, but the language employed in applied ethics has inevitably changed. Nor is it appropriate or sufficient to develop a code of professional ethics in the hope of dealing with the intricate problems of complex social practices.

During these initial decades and up to the turn of the century, public health and bioethics ignored each other, except for sporadic academic events unimaginatively concerned with the professional ethics of epidemiologist and public health officials: honest research, collegial competition, scientific solidarity and acknowledgment of peers' originality and priority. Publications dealing with specific issues related to public health were gathered into anthologies [Beauchamp \& Steinbock, 1999] but such efforts were insufficient to lay the 
foundations of a new field of inquiry or to offer a systematic and normative approach to the ethics of a complex social practice, prompting a leading figure of public health to lament that "public health cannot develop an ethics until it has achieved clarity about its own identity; technical expertise and methodology are not substitutes for conceptual coherence." [Mann, 1997].

The first generation of publications devoted to the subject of normative ethics in public health, presented a corpus of professional ethics [Fayerweather, Higginson \& Beauchamp, 1991] that led to the elaboration of the American Public Health Association Code of Ethics [Kass, 2001]. The main thrust of this effort was to present the ethical implications of public health activities, and to emphasize the need for a normative blueprint to act correctly in the practice of its scientific, technical, economic, and political activities. Beyond these normative efforts, it now seems appropriate to apply terms and concepts of bioethics in dealing with the ethics of public health, the quest for excellence and the deliberation on rights and duties, autonomy, beneficence and fairness due to all those affected by biomedical practices. Bioethics deliberation on public health activities engrossed in the prevention of disease and the promotion of health, will only be true to its self-set goals if it addresses the needs and desires of all those involved: providers, planners and practitioners, beneficiaries, the common weal and, as some scholars are proposing, the ultimate and perhaps illusionary attainment of global justice.

Public health itself has also come under scrutiny because it takes for granted that its constituent terms are clear and univocal. But that is far from true; indeed, there have been many proposals to change the name of the discipline to social, communitarian, collective, population or even global health, and cogent arguments in favor of each of these denominations are presented. Does 'public' refer to a group, an association, a community? Or does it refer to the actual, or perhaps only the legal, inhabitants of a nation? Should one refer to regional or even global population as the public?

Health is an equally elusive concept, poorly served by the holistic World Health Organization's [WHO] definition -well-being at the biological, psychological and social levels-, which begins by being counterintuitive in its denial of health as the absence of disease, and the neglect of common sense acceptance that people who are not sick should be considered healthy. There are intermediate positions based on well-thought arguments that resist perfunctory dismissal, but have been discussed elsewhere [Caplan, Engelhardt Jr., McCartney, 1981]. Refined diagnostics and molecular biology dictate that latency and predispositions will render relative the idea of absent disease. And, at the other end of the spectrum, the boundaries of what health means are expanded by developing selective and enhancing interventions in a quest for excellence and performance beyond normalcy.

A fairly succinct and traditional definition of public health sees it as "the science and the art of preventing disease, prolonging life and promoting physical health through organized community efforts" [Winslow 1920, cited in Gostin, 2002]. What is the place of art in a discipline that is based on scientific research yielding information for technically efficient interventions? Prolonging life hardly seems a primary goal of public health, it is rather a consequence of well-designed policies and programs carried out in a socioeconomic and ecological favorable environment. And do organized efforts of society mean that citizens take care of themselves in healthcare issues? An even more Spartan definition may ease the way into a better focused and more fruitful discussion: "Public health is what we, as a society, do collectively to assure the conditions for people to be healthy." [Institute of 
Medicine, 1988, cited in Gostin, 2002]. Interestingly, ethical emphasis is added by confirming "[S]ociety's obligation to assure the conditions for people's health." [Gostin, 2002].

Some preliminary insight may be gained by briefly reviewing the history of public health and the development of bioethics. But historical perspectives should be approached with caution, for different parts of the world will show unequal levels of public health development. National societies simultaneously harbor a variety of policies and approaches to public health issues, due to differing socioeconomic determinants of health and disease, to contextual and often arbitrary allocation of resources, and to the profound impact of social, health and healthcare inequities and gradients. Especially in less developed countries, traditional public health efforts at controlling infectious diseases will coexist with a high prevalence of non-communicable morbidity, due to class differences where whole segments of populations live in colonial-like poverty while others, few but influential, belong to the exclusive caste of the immensely rich. Disparities in income show a Gini Index of 0.45-0.50 (gross inequity) for Latin American nations compared to around 0.30 (moderate inequity) in developed countries.

\section{The development of public health}

Plagues, a word rooted in pläga meaning divine punishment, were believed to be caused by godly wrath as punishment for human misdeeds; such major catastrophes were to be suffered without eliciting action beyond repentance and prayer. Egyptian theurgy recognized Sekhmet as the goddess of pestilence, easily aroused and requiring careful and devoted appeasement. Hippocratic writings show clear awareness that diseases do not only befall the individual human body, but also may lodge in communities -endemics- or suddenly strike whole populations -epidemics-, this being due to the local peculiarities of "airs, waters, places" as discussed in "An essay on the influence of climate, water supply and situation on health". The Hippocratics classified diseases that were of necessity incurable and mortal -kat'anánken-, in contrast to fortuitous disorders amenable to medical ministrations -katà tykhen-. In "Epidemics", diseases are dramatically depicted, mostly running a relentless course towards death. As so often in Greek medicine, the physician's concern is limited to recognizing the disease and predicting its outcome, lest he be made responsible for injudiciously interfering with untreatable conditions [Lloyd, 1978].

The awareness of population health and disease was broached more pragmatically by the Romans, who assiduously followed Cicero's dictum salus populi suprema lex est -health of the population is supreme law-, where salus referred to well-being, but also to salvation and health. Romans' incipient public health measures were directed towards securing water supply, supervising public baths, and building sewerage systems to keep a clean city. Thus, Augustus and his aediles appeared to ignore the belief held in antique societies concerning the divine origin of diseases and man's impotence to deviate the course of natural events.

Nevertheless, the Middle Age recurrently mingled magical thinking with faith and the belief that diseases were caused by fatum or destiny, that is, divine punishment for moral turpitude, as compared to morbid conditions due to fortuna or chance, where medical interventions were indicated. Hygienic measures were for the most part practiced in monasteries, leaving city dwellers unprotected. The great pandemics that ravaged Europe well into the $17^{\text {th }}$ century were described as "visitations that struck from" heavens, which did not abate till the moment it "pleased God", for "vain was the help of man" [Defoe, 
1722]. City administrators registered the appearance, dissemination, and final disappearance of these virulent bouts, seeing their main task in isolating the sick and instructing the healthy to emigrate, or at least keep to themselves, and applying measures aimed at preventing contagion even though the actual mechanisms of transmission were unknown. In his much celebrated History of Public Health, [Rosen] (1993) prefers to speak of prophylaxis rather than prevention, for the traditional public health measure in the wake of epidemic outbursts was confined to establishing barriers to isolate the sick and protect the healthy. Prophylaxis resorted to quarantine, sealing infected houses, interning the sick in hospices, leprosy-houses -lazzaretos-, pox-houses -Blaternhäuser- and wood-houses Holzhäuser-. Daniel Defoe's account of the bubonic plague that ravaged London in 1648, depicts public health officials dictating strict measures of defensive prophylaxis while helplessly observing the course of events. Isolation was so drastic as to be resisted as immoral, for if disease was suspected in one individual, the whole house-hold was locked in, incarcerating all its inhabitants including those not yet afflicted. Fleeing infested cities was another prophylactic measure, mostly reserved for the affluent, often condemned by Reformist Christians who believed that fate, not human decision, would spare the worthy. Other dignitaries of the cloth took the opposite view, urging their parishioners to fulfill their religious duty of escaping to avoid infection and death [Cunnigham \& Grell, 2000].

Epidemics were due to external factors, much as Hippocrates had suggested, leading Sydenham to speak of an atmospheric "epidemic constitution", the origin of which were emanations from the earth, the miasmas. The atmospheric-miasmatic theory survived up to the 19th century, complemented by the idea of some self-propagating and transmissible particle which Fracastoro in the $16^{\text {th }}$ century considered to be a seed or seminaria, as was eventually proven by Pasteur, Koch and the nascent discipline of bacteriology.

This brief account illustrated the intertwinement of public health problems with moral and religious considerations, superseded but never quite eliminated by modernity's reliance on reason and science.

\subsection{Political dimensions of public health}

Rosen considers the political birth of the nation-state as the most important impulse for the rising awareness of public health challenges that led to disciplined programs of hygiene and the policing of population behavior. After the Peace of Westphalia (1648), empires were replaced by nation-states with clearly demarcated, although often disputed, territorial limits and the political mandate to take care of the inhabitant population. The State required political administration based on policies and revenues, both aspects needing a quantitative evaluation of populations in terms of demographic data and productivity, as well as estimates of available resources. Being, as Rosen quotes, "the art or reasoning by figures upon things relating to government", it is hardly surprising that the term "statistics" should have been coined by Achenwall in 1749 "to designate the descriptive analysis of the political, economic, and social organization of states."

Trade and commerce were the most important activities in European countries during the Renaissance, benefiting society and the state by way of accumulating power. The politics and economics of power known as mercantilism were carried out for the benefit of an authoritarian sovereign; in Germany, the term cameralism aptly described the nation's productive efforts at filling the emperor's coffers. Such an efficient production machinery 
required the working population to remain healthy and disciplined, inspiring B. Ramazzini to publish the first comprehensive treatise on occupational medicine (1700), and J.P. Frank to present his System einer vollständigen medicinischen Polizei (1779), which ran through six editions in 30 years [Carrol, 2002].

As the State took over the governance of its people, it began to record birth and death data, culling demographic statistics of population health and disease conditions, in order to give substance to a new form of politics that came to be known as biopolitics [Foucault 2008, cited in Macey, 2009]. During the 19th century, the triumphs of public health measures based on the theory of miasma were superseded by bacteriology and the demonstration that the transmission of infectious diseases was due to contagion by microorganisms. Further demographic and epidemiological developments inaugurated the present era of chronic diseases resistant to curative efforts, leading to intense scientific research, and major changes in public health strategies. Thus, three eras of public health are recognized, presenting epidemiological turns in the wake of demographic and socioeconomic developments:

- $\quad$ Medical police and biopolitics $-17^{\text {th }}$ to $19^{\text {th }}$ century-.

- Infectious diseases and the search of a causa vera inspiring epidemiological research in the $19^{\text {th }}$ and initial $20^{\text {th }}$ century.

- Degenerative diseases informed by multicausal thinking, extensive epidemiological research, increased awareness of socioeconomic determinants of health and disease and, in due time, the development of a new public health culture.

The purpose of the present text is to follow the bioethical implications of these demographic and epidemiological transitions which are less clearly demarcated in underdeveloped countries, where endemic infections coexist with a mounting prevalence of chronic degenerative conditions.

\section{Bioethical issues in public health}

Clinical ethics had evolved from the placid and bloodless sort of medical ethics known since Hippocrates, through Percival and up to the first half of the 20th century, when a new era of scientific medicine woke up to a host of quandaries about the right thing to do, facing the requirements of a more sturdy moral discipline that led to the birth of bioethics in the early 1970s. Clinical bioethics became involved in unsettling issues like autonomy and fairness, the elusive concepts of health and disease, care of the disadvantaged and the mentally incompetent, the responsible attitude towards biomedical research subjects, the relevance of biomedical investigations. Academic bioethics flourished, getting so involved with scholarly fine points of theory, that it seemed to lose touch with reality and become irrelevant to the needs and worries of the biomedical practices it was expected to study and influence [Hedgecoe, 2004].

Few scholars resisted the temptation of simply transcribing bioethical principlism to the public health agenda, failing to remember that the so-called Georgetown mantra was itself an adaptation to clinical practice of the Belmont Report (1978/79), issued as a ethical guide for biomedical research with human beings. The Belmont Report and the shortly thereafter presented and highly influential principle-based brand of bioethics addressed the one-toone, face-to-face doctor/patient and researcher/subject relationship, thus offering scarce 
enlightenment to the collective and anonymous practices of public health programs [Beauchamp \& Childress, 2001].

Ethical problems applied to the many diverse aspects of public health practices, can basically be grouped under five headings. The most pervasive and amply recognized area of conflict occurs in evaluating the common good and its requirements versus individual autonomy. Secondly, the tendency of public authorities to impose policies often clashes with scientific information, or lack of it, about what to do or omit. Thirdly, the eternal dichotomy of natura/cultura is reenacted as epidemiology explores biological, especially molecular, predispositions and risk, with diminished concern for sociological factors that influence these dispositions. Fourth, socioeconomic determinants are presented and contrasted with theoretical suggestions of reforms, empowerment, the quest for justice and health equity, at the same time forging public health policies that seek to promote health by influencing freely adopted life-styles. Finally, the impact of globalization and its consequences on human rights approach to public health will be briefly discussed.

\subsection{Collective goals and individual autonomy}

The crux of public health bioethics may well be the conflict between individuals and society, for public health is always a collective enterprise that needs to be implemented by acting on individuals or requiring their cooperation. Immunization is a typical public health intervention, but it consists of vaccinating individuals. In the era of epidemics, the severity of plagues was assessed by recording the number of deaths occurring per unit of time, based on the idea of society as an aggregate of individual human beings. The strong resurgence of neoliberal politics has given new impulse to the idea of monadic individuals who are assembled rather than interrelated: "particular interventions aim at the health of the public...they should promote health on such a scale that it is visible in aggregate population health figures." (Veveij \& Dawson, 2007).

The final aim of public health does not differ from medicine's efforts and goals to prevent and treat disease, and promote health in the individual, the difference rather being that public health addresses the collective factors that influence health and disease, and promotes communal interventions that could not be carried out by individual efforts alone. Recognizing the complex interaction between the common weal and individual autonomy focuses the basic ethical perspective needed to analyze, justify and orientate the moral solvency of public health.

By definition, public health addresses issues that affect society at large, specific communities, or groups. Although helpful interventions are expected to benefit most members, it does not follow that specific individuals will be among the favored, as the wellknown "preventive paradox" illustrates: "A preventive measure which brings much benefit to the population offers little to each participating individual,"[Rose, 1985] One of the reasons bioethics needs to be incorporated into public health is to provide rational ethical arguments that should help clarify when public health is justified in imposing policies as compared to situations where individual autonomy is reasonably invoked in opposition to public demands.

Social interests and care of the common weal are habitually understood as responsibilities of the State acting through democratic, and hopefully participative, governmental institutions. A new field of controversy is thus created, because the State may be constitutionally liberal or even libertarian and therefore partial to only minimal intervention in social affairs, or it 
may harbor a strong social persuasion to provide more expansive welfare tasks. Accordingly, health protection and care can be carried out by governmental institutions, private initiative or a mixture of both, involving a variety of political views and ethical concerns. Throughout history and in different societies, the balance between the collective/individual, and the State/market alternatives has shifted, creating polemics and requiring normative adjustments, as well as ethical reconsiderations.

Even if a public program appears to be widely beneficial, certain individuals may wish to be exempted, preferring to seek the same benefits on their own. For example, massive vaccination may be individually objected on the ground that privately purchased immunization is more convenient. Others might seek exemption because they do not believe in the expected benefits, or fear harmful consequences -allergies, negative reactions of underlying disease, or unpleasant side-effects-.

Believers in public action will argue that the common weal ought to take precedence over individual preferences, and such a position is probably justified provided that: a) it is demonstrably certain that the public will benefit from the intended action; $b$ ) the program may be less effective if individual dissent is accepted; c) dissenters have valid arguments that could survive the scrutiny of expert questioning. Therefore, public health measure that are compulsory when disciplined and universal participation is technically necessary to ensure effectiveness, leave little room for individuals opting out. In health promotion activities, on the other hand, where the public is merely being informed and certain conducts are recommended but not enforced, dissenters may freely ignore such campaigns.

It has been recognized that "(given limited resources) monies allocated to public health may come at the expense of monies for treating acute clinical care." This clearly sets out a dichotomy of community versus the individual [Boylan, 2008]. The tension between individuals and society is not only a matter of conflicting personal cooperation or dissent with needs and goals of the common weal, it may also involve resources allocation. The right to receive urgently needed scarce resources will conflict with the public mandate to reasonably ration resources in order to assign them in the best interest of all.

Scholars have defended privileging the endangered individual to the detriment of public benefits. For the sake of rhetoric, "rescue" is limited to life-saving interventions under the assumption that no alternative can trump over preserving life [Quigley \& Harris, 2008]. The situation is a special case of the more general dilemma between allocating resources to public health endeavours or to medical therapy, a dilemma that, but for rare exceptions, has been consistently solved in favour of tertiary medical care. In fact, many nations allow insufficiently funded public health to coexist with costly and sophisticated medical services. In defending rescue medicine, it is postulated that its beneficiaries are identifiable, whereas public interventions are "statistical and non-identifiable" but, if this argument is allowed to prevail, funds would invariably flow to individual treatment, for the common weal pursued by public health is always anonymous. Secondly, it is said that rescue interventions are of immediate or short-term benefit, whereas public prevention measures are effective, if at all, in the distant future. In spite of its numerous critics, discounting the future is a valid argument, but not because future generations are too distant to stimulate protection, but because vast number of actually living human beings are in dire need which cannot be bypassed in favour of the undetermined future. Discounting the future is further justified because expected benefits for as yet unborn generations will also obtain from present environmental policies. Failing to discount the future means planning benefits for future generations at the cost of neglecting contemporaneous needs. Securing resources for the 
future is only reasonable and justified if presently unmet needs have been covered. Environmental ethics, for example, envisions policies and interventions that will improve natural conditions for living beings in the future, but the actual implementation of such measures will be of present benefit as they reduce rates of deterioration, pollution and exploitation.

\subsection{Public domain and private realm}

The potential conflict between collective goals and individual rights to non-interference has been presented as two opposing sociological perspectives. Under the influence of Marx and Durkheim the unit of observed action is always society, i.e., the individual as part of, and determined by, social ties. In contrast, the individualistic approach conceived by Pareto and Weber prefers to understand human actions as initiated by singular persons, modulated but not determined by their social circumstances [Van der Maesen \& Nijhuis, 2000]. In the first view, economic and social influences inform and permeate each human being, whereas emphasis on the individual entails recognizing free will that is autonomous and called upon to resist coercion from external determination.

The collective/individual dichotomy is closely related to the issue of public domain versus private realm, state-centred political arrangements versus libertarian non-interference, finally debating upon the proper area of concern for healthcare as a public intervention versus an individual, self-responsible enterprise.

Ever since the mid 1800s, public health began collecting statistical data on biological processes such as birth and mortality rates, health conditions, and life-expectancy, leading to political interventions described as "population biopolitics" [Foucault, 2008, cited in Macey, 2009]. The prevention of epidemics, the fluoridation of water supply, the imposition of safety measures, or the regulation of production and distribution of food and drugs are some examples were disciplined cooperation of all citizens is required, avoiding any form of individual non-compliance, lest the public health goals derive in failures and increased risks. Enforcing public health measures considered to be essential may entail impositions and sanctions, coercing individual autonomy to a point that many citizens might resent. From a sociological point of view, the public space has been expanding its field of influence to include and invade the private realm with the purpose of inducing, even regulating, personal conduct. Dissuasive recommendations and legal restrictions are part of the political life of many nations, affecting personal decisions in areas like reproduction, sexuality, disease, and dying. "The distance between civil society and the State increases, whereas the separation between private and public life is disappearing." [Touraine, 1985]

These are more than merely academic debates, for many countries, especially of the Third World, validate strict and mandatory public health policies regarding suicide, euthanasia, the right to reject life-saving medical intervention, abortion, assisted reproduction, availability of contraception, organ donation. Evidence has been presented that under the banner "culture of life", prosperous countries have earmarked political, economic, and public health support to poor populations, by requiring recipient countries to actively combat prostitution, prohibit abortion, or promote abstinence as the primary preventive against HIV infection [Purdy 2008].

In view of such ethical transgressions of public health interventions, it is hardly surprising that individual autonomy defenders should become suspicious and vigilant, leading to unsettled opposition between public health policies and the preferences of civil society's members. The abortion controversy is a prime example of social desires and needs that are 
opposed by recalcitrant public policies, leading to unsafe clandestine interventions, unwanted children and child abuse, socioeconomic deterioration, and increased suffering of families living in poverty. The pro-life / pro-choice polemic is a clear illustration of an unresolved and ongoing clash between the social vocation of religious and conservative institutions to safeguard a "right to life", and the claim for unhindered reproductive decisions in the private realm.

At the political level, collectivism tends to support a strong, democratic and participatory State, engaged in promoting the common weal in an atmosphere of social justice that is expected to meet the basic needs of all citizens. A strong State is essential in nations where inequities marginalize and disempower important segments of the population who are in need of support to gain access to basic goods: nutrition, healthcare, education and social security. Neoliberalism as well as its libertarian version, reject any intervention beyond the minimal State that protects life, patrimony and national territory, expecting individuals to seize equal opportunities and autonomously shape their lives. Libertarianism presumes all inhabitants of the nation to be citizens, i.e., have their basic rights respected and their national affiliation recognized, enabling them to have unhindered access to the social arrangements that guarantee law and order. Public health is profoundly affected by these divergent views regarding the political, philosophical and bioethical aspects it must consider, as can be illustrated by reviewing the evolution of epidemiology, and changes in its research objectives.

\subsection{Epidemiology: Quest for knowledge}

Epidemiology has evolved into a scientific inquiry focused on the demographic distribution and causes of disease and health related processes, gathering evidence to inform and sustain public health in its preventive and promotional activities. Influenced by demographic transitions, epidemiology has been modifying its epistemological perspectives and research methods. Different denominations and taxonomies have been proposed, one of the most illustrative being presented by Susser \& Susser [1996], who characterize the evolution of epidemiology in four eras, each developing its own paradigm:

\section{EPIDEMIOLOGICAL FOCUS}

Sanitary statistics

Infectious diseases

Chronic diseases

Eco-epidemiology

\section{CONCEPTUAL MODEL}

\author{
Miasma \\ Germ theory \\ Black box \\ Chinese boxes
}

As previously mentioned, political engagement in hygiene and sanitation based on the miasma theory served to discipline and police the population in the early times of modernity. In the 19th century public health was mainly concerned with infectious diseases, as biomedical research was aiming to find the causa vera of diseases, and epidemiology refined its observations on the ways infections were transmitted. Pasteur's bacteriological research and Koch's postulates suggested that infectious diseases were due to identifiable 
microorganisms, and inspired the search for a specific therapeutic agent, the magic bullet pursued by P. Ehrlich.

These efforts influenced a major demographic and epidemiological transition as the disease pattern shifted from infectious diseases to non-communicable, degenerative and chronic conditions. The monocausal approach to the now prevalent diseases was hopelessly inadequate as it became apparent that many socioeconomic and environmental factors were involved, a fact that was common knowledge but had not been systematically studied. Multicausality was first thought to be structured in an orderly cause-effect sequence but, as the complex relationship of necessary, sufficient and confounding factors was recognized, epidemiology submerged causal interactions into a black box. Scientists were forced to modify their rigorous cause-effect language, and turn to statistical estimates of probability dealing with as yet poorly identified external circumstances and hosts of conditions that triggered disease processes.

The black box metaphor refers to the awareness that health and disease are complex processes of multicausal origin rooted in biology, environmental and socioeconomic contexts, psychological and behavioural processes. Empirical evidence as to the influence of social and economic factors has been so widely accepted as to constitute an array of determinants firmly anchored in reality and resistant to change. New metaphors -networks, Chinese boxes, complex systems-, and denominations like 'eco-epidemiology' have been proposed in order to explain multilayered influences and intricate interactions. The natural and social environmental factors became recognized as strongly pathogenic, and the ideas of eco-epidemiology were introduced and filled with ominous descriptions -unassailable social determinants, global climate changes, irreversible decay of nature-, thus unwittingly supporting a conservative ideology that accepted the status quo and discouraged major remedies. The complexities of underdetermination and uncertainty deprived epidemiology of precise and convincing suggestions for preventing diseases and promoting robust healthcare measures, thus denying public health the ethical justification to recruit resources and transform uncertain knowledge into interventions that often become arbitrarily compulsory.

An unedited turnabout occurred as epidemiology became engrossed in studying risk factors and shifting emphasis from external determinants to individual predisposition and exposure. Emphasis was deflected from seeking cause-effect relations to identifying factors of health risk, giving rise to what is now called "risk factor epidemiology" that operates with a penchant for refined probability statistics [Susser, 1998]. Risk is the probability of suffering a negative or deleterious effect and, when uncertainty prevails, there is a tendency to collapse probability into possibility, which means that an event may occur but we have no clue as to the likelihood of it actual occurring. Socioeconomic and environmental risk factors are external to individuals and resistant to modification, as insinuated by naming them determinants rather than conditions. Consequently, risk factors were internalized, research now turning to investigate individual predispositions to deleterious external circumstances. Public health is frustratingly helpless beyond confirming that the poor are especially vulnerable to disease and less able to take care of their health as long as profound socioeconomic changes remain absent. Major changes in the social structure and the distribution of resources are formidable challenges, depending on governmental power and resolution to seek social justice and healthcare equity.

Epidemiological research has come to be considered the irreplaceable scientific basis of public health activities. The bioethics of biomedical research is becoming a major area of 
deliberation, facing problems that also involve epidemiology: informed consent of individuals and communities, relevance of research projects, private versus public funding, sustainable risks, benefits for research subjects and host communities, and a number of other issues that require ongoing attention. Some of them are briefly mentioned throughout this text, but a few remarks on two salient controversies seem in order: evidence-based epidemiological research, and offshoring.

Evidence-based clinical research has yet to find its place in medical practice and healthcare policies. Hailed as the indispensable foundation of medical knowledge, it has found supporters but also many critics, especially amongst practitioners who lament that experience, contingencies, ethical considerations and patient participation are underrated as decision-making criteria in this scientific approach to treating and caring for the sick. Nevertheless, there is fair agreement that hard evidence is necessary to plan allocation of scarce resources and to set priorities in healthcare programs when legitimate demands exceed availabilities, in which case decisions to ration must rest on well sustained knowledge about efficacy -cost/benefit ratio-, and effectiveness -problem-solving capacity-. Rationing is a complex issue when resources are insufficient to cover essential medical needs, for privileging certain areas will leave others to the dangers of neglect and deterioration.

Evidence-based epidemiology is an elusive goal, since population health is based on complex interactions of many variables and determinants which are practically impossible to dissect for experimental purposes. The quest for probable cause-effect links, in clinical research often focused on dose-response relationships, isolating variables and employing RCT (Randomized Control Trials), is usually insufficient in determining collective disease mechanisms, because statistical probability needs to be supported by plausibility -non randomized observations- and, most important, by adequacy -demonstration that intervention is being effective- [Victora, Habicht \& Bryce, 2004]. These technicalities boil down to the fact that linear cause-effect answers rarely satisfy the complexities of public health problems.

Epidemiological research has responded in two ways to these quandaries: First, by accepting external socioeconomic and environmental conditions as given determinants, thus shifting risk factors to the individual where predispositions and disease facilitating behaviour yield information that may be employed in preventive medicine by modifying individual response to rigid external factors. As previously noted, risk factor epidemiology centred on individuals tends to reduce State protection, induce self-care and reinforce the tendency to blame the victim. Secondly, by applying scientific methods in such a rigorous way that reliable internal validity is secured. But, as internal validity increases, results loose external validity, that is, in order to isolate the explored variable, study conditions have been artificially purified in such a way that they differ from real-life conditions to the point of making it implausible to extrapolate results from bench to bedside [Rothman, 1991].

A related problem is offshoring, an inelegant euphemism representing the rapidly increasing tendency of sponsors to carry out research in poor countries, where costs are reduced, ethics standards may be less stringent, and recruiting subjects appears less problematic [Petryna, 2007]. These research protocols, very often carried out by professional research institutions $(\mathrm{CRO}=$ Contract Research Organizations), do not heed local needs in their quest for results that are marketable in the original sponsor countries, thus reinforcing the 90:10 divide and the further neglect of the healthcare needs of poor populations. 
In view of these new scenarios, a novel form of preventive medicine was developed: accepting that external risk factors were resistant to change, epidemiologic research concentrated on finding out why some individuals and social groups are more susceptible to deleterious circumstances than others. Procedures were developed to identify those at risk, and diagnostic probes refined to map personal vulnerabilities and detect predispositions, focusing on preclinical conditions and early disease manifestations. Molecular biology came to the aid of exploring the biological constitution and genetic flaws of singular human bodies, to the point where rarely anyone manages to emerge with a clean, albeit provisional, health certificate.

\subsection{The "new public health"}

Post-World War II most European countries became social and well-fare States, though 50 years later financial limitations forced reductive policies, restricted coverage, and increased co-payments for medical services. The undisputed hegemony of neoliberal politics has been wary of too much State intervention, preferring to promote market centred laissez faire policies that clip the wings of many public health initiatives. A "new public health" was born, with a neoliberal vocation to shift public health involvement "from the state to members of the public themselves" [Petersen \& Lupton, 2000]. This major change in public health philosophy and strategy was strongly supported by the newly developed risk factor epidemiology. The individual at risk is called upon to embark in self-care instead of claiming State protection, every citizen being responsible for a health promoting life-style and advised to seek medical assistance by his own means. As social protection pales, private enterprise flourishes in all areas of medicine and healthcare, thus inevitably exacerbating the inequalities of access and coverage in medical matters [Pearce, 1996].

The marketing of healthcare has influenced biomedical research, which is to an increasing extent dominated by the pharmaceutical industry catering to the needs and desires of the well-off, developing and promoting enhancement medicine, and neglecting research of major and pressing public health problems such as malaria, dengue, and other endemic diseases that ravage poor populations. The term "neglected diseases" was introduced to illustrate the deficiencies of global public health, a term that covered such chilling data as the daily death of 16.000 children from hunger-related causes (Illies, 2008], or of half a million women dying during pregnancy and in childbirth for lack of simple preventive measures [Purdy, 2004].

Medicalization and lucrative enticements for marketing preventive and therapeutic medical interventions have severely increased inequities in healthcare, aggravated by massive brain drain of healthcare professionals. The exorbitant rise of medical care costs are stranding marginal populations, in addition to stimulating medical tourism that entices affluent patients to seek medical care in less developed nations.

Petersen and Lupton [2000] reach the harsh conclusion that "[W]hile new public health authorities and agencies continue to adopt overtly coercive strategies such as quarantine, isolation and enforced medical treatment when they seem required and most justified..., they are equally, if not more, reliant upon the use of strategies that position citizens as acting of their own free will and in their own interests to protect their own health." Public health bioethics must face these accusations and unveil such strategies as are, if not always 
coercive, steeped in manipulative intents that are ethically suspect and often harmful to individuals and whole populations.

The general trend is to reduce State responsibility in public health matters. Even though recognizing social and economic determinants of health and disease conditions, epidemiological emphasis and new public health proponents are accepting external risk factors as circumstances that individuals have to cope with by actively mitigating their predisposition to be affected by these deleterious circumstances. Adherence to preventive actions and early diagnostic explorations, pre-clinical medication, changes in diet, behaviour and life-style are the bulwarks of responsible self-care. Medicalizing public health increases the vulnerability of citizens with scarce resources, who no longer can find refuge in comprehensive State protection that is either reduced or denied.

\subsubsection{The human rights approach to healthcare}

From a more global perspective, it appears that different public health paradigms co-exist with changing emphasis throughout time and, to a major degree, in dependence of socioeconomic and cultural diversity. Hygiene, sanitation infrastructure and public health policies mirror the civilization of their time and are strongly determined by the values and beliefs of their social environment [Sigerist, 1960, cited in Mechanic, 1978]. The multicultural trend of modern times, and the coexistence of extreme socioeconomic disparities within societies and across nations, provide strong evidence that public health paradigms overlap and are enmeshed in a permanent turmoil of vested interests, ideological and political motivations, as well as powerful economic influences.

In the second half of the 20 2 th century, Western democracies in Europe expanded social services under the concept of welfare State, including free, universal and comprehensive medical care. For a variety of reasons -massive illegal immigration, lack of resources and personnel, increased costs-, coverage became progressively restricted, although certain basic functions of public health have remained uncontested: immunization, massive screening programs, essential life-saving but extremely expensive interventions and medications like antiretroviral therapy. Although breached in practice, the idea of governmental responsibilities in public health and medical care, especially for the poor and economically feeble population, has remained a valid social and political goal, mainly nurtured by respect for human rights and recognition of a basic right to health [care].

Whether public health [bio]ethics can be adequately and sufficiently grounded in human rights is a matter of ongoing controversy, ranging from the belief that the human rights approach is at the ethical basis of public health, to the objection that rights-talk is too weakly binding to achieve practical results and political commitment, and should be replaced with duty-talk demanding the provision of certain basic public services [Mann, 1997; O'Neill, 1998].

The human rights approach has been counterproductive [Gostin, 2002], because it is unfocused and excessively political "by espousing controversial issues of economic redistribution and social restructuring" [Hessler, 2008]. In fact, international human law has failed to commit national states to binding and enforceable norms; as for the international community, it has been unable to actually inspire political action and social reform, as tragically illustrated by the fact that over 60 years after UNESCO's Universal Declaration of Human Rights one third of the global population suffers from starvation or severe malnutrition, and no less than 3.000 .000 children die every year from preventable diseases 
[Illies, 2008]. A number of scholars believe that more robust philosophical accounts of human rights are required, stressing that a purely utilitarian approach is too narrow to anchor public health ethics in human rights, especially if moral deliberation is neglected because excessive trust is placed in legal documents.

Acknowledging that "[B]ioethics has gone global", Arras and Fenton support Mann's original idea that bioethics ought to be seen as fundamentally related to the public issue of rights to healthcare, but their analysis leads to some discouraging conclusions: "a right to healthcare goods is incompatible with the unfortunate likelihood that it will not be honored for the majority of the world's poor for many years to come." Therefore, "the lingua franca of human rights, while important and helpful in many ways, is not a sufficient methodological tool for a globalized bioethics." To be effectively action-guiding, human rights need to be embedded in social institutions which in turn are context-bound in their problem-solving capacities. Nations with sparse public health resources will be unable to meet the actual needs and claims that are based on human rights doctrine, leading to the conclusion that "institutional human rights are not, strictly speaking, unmodified human rights. They will, rather bear much more resemblance to political rights" [Arras \& Fenton, 2009]. Realpolitik trumps over ethics, leaving global proposals based on human rights to dry out as empty concepts.

\subsubsection{Globalization and human rights}

Economic expansion and political globalization including the undisputed hegemony of capitalism ever since the collapse of the Soviet Union and East European socialism, has created what N. Fraser has called a postwestphalian macro-political world order [Fraser, 2009]. Transnational business associations in the wake of tendencies to globalize economic strategies and political systems, have had profound impact on many aspects of health, disease and medical care around the world. Globalization has also allowed the powerful to exercise pressure on smaller nations, instigating them to accept the rules of macroeconomy, with their consequences and side-effects.

Public health has suffered from insufficient financial support and a trend towards further reduction of national resources as a consequence of globalizing market policies, as well as the diversion of healthcare monies to insufficiently substantiated promotional campaigns, and to the expansion of extensive anti-bioterrorism strategies. It is well known but rarely publicized, that international banking policies have provided loans to developing countries under the condition that State intervention be reduced, allowing private enterprise to flourish in the market for medical and other social services [Almeida, 2002].

Frequent concern has been voiced about the trend towards privatization and the enormous influence of big medical business, including the pharmaceutical industry, genetic research and its applications, which have marginalized public health efforts at the same as they encourage ideological discourses in favour of global bioethics and global justice.

Global justice, global [bio]ethics, international health equity and similar wide-ranging ethical proposals include acknowledging and fulfilling obligations to the poor, and considerations about distant ethics. These ideas are nurtured by well-known basic facts: socioeconomic determinants of injustice and health inequalities, responsibilities arising from historical political processes -colonialism-, and present economic strategies such as concentration of financial power, monopolistic practices of drug companies and transgenic food producers, big-stick politics in pollution and exploitation of natural resources. And yet, 
in the wake of powerful and unrelenting economic processes, thinking in terms of global ethics remains an inconsequential academic exercise.The impact of these determinants and macroeconomic policies has been shown to have a nefarious influence on the health condition of the world population, creating inequalities that go hand in hand with increasing social and economic disparities. Wealth and health develop together, as do disease and poverty. Although it remains controversial whether poor health is a major cause of poverty or, to the contrary, lack of essential goods leads to sparse healthcare and precarious disease prevention, it is obvious that a vicious circle ensues between poverty, endemic diseases, lack of resources for medical care and public health programs. International agencies and a number of scholars interested in applied ethics have stressed the urgency of developing acutely needed palliative, remedial and redistributive policies.

An early, general and underdetermined suggestion by the WHO posits that "health inequalities count as inequities when they are avoidable, unnecessary, and unfair". Such a candid statement may serve as food for thought, but it will hardly fuel effective strategies to reduce inequities and improve levels of public healthcare: as socioeconomic inequality increases throughout the world, the gradient of health inequality becomes steeper. Does this well documented and often lamented state of affairs generate a transnational obligation to reduce or resolve inequalities or, at least, take steps to avoid that inequity occur, persist and even increase [Singer, 2004; Pogge, 2005]?

Some influential ethical doctrines like Rawls' justice as fairness are meant to apply within national boundaries or, as Nagel puts it, to citizens who "stand in the explicit relation to each other that is characterized by a state". This "statist" perspective is contrasted to a "cosmopolitan" view committed to the belief that justice ought to be a global aspiration, requiring "adequate primary healthcare and basic education [as] preconditions for living a good human life" [Daniels, 2006].

Claiming that many contemporary problems occurring at an international scale render a statist attitude obsolete, globalism envisions "transnationalising the public sphere", in order to foster "new transnational public powers, that possess the administrative capacity to solve transnational problems" [Fraser, 2009]. Public health, which might continue to qualify as a national issue to be approached in a statist fashion is, nevertheless, extremely sensitive to international influences. Control of infectious diseases, for example, is considered to require "comprehensive global efforts" that transcend national prevention programs [Battin et al. 2008]. On the other hand, the 90:10 divide that shows most biomedical research resources to be assigned to the study of health problems affecting the wealthy, is a palpable and depressing illustration how transnational actions deepen inequities by being oblivious to the health needs of the have-not.

In an effort to salvage the cosmopolitan view that international health inequalities ought to be addressed in transnational efforts, Daniels [2008] suggests a minimalist commitment to discourage policies that harm poor nations -brain-draining, aggressive property rights and patent-mongering that limit access to drugs-. In addition, he hopes for the development of a "more promising [relational justice] approach", that will require fair amounts of philosophical groundwork facing vested interest and political divisiveness. Even such well meant top-down approaches remain in the academic realm, for they lack the urgency of those in dire need that require bottom-up practical solutions. 
Much writing about universal healthcare rights appears as wishful thinking in the wake of unfulfilled promises of international cooperation and sustained foreign aid commitments [Gordon, 2008]. At a more specific level, offshoring research projects has failed to provide significant post-research benefits to host populations as persistently solicited by the Declaration of Helsinki (Paragraph 17). Furthermore, the Declaration's Paragraph 33 sharing of post-investigational benefits-, apart from having been watered down in the 2008 version, is regularly honored in the breach, ignored and even vociferously downplayed.

Arguments on global issues are self-interested and myopic, for most nations will agree that a pandemic threatening rich and poor needs to be prevented by collaborative actions. Wealthy nations are willing to engage in military actions in foreign countries, purportedly in defense of global democracy and basic first generation human rights, but will not be equally enthusiastic to participate in supporting improved healthcare and public health programs that honor a right to basic needs including primary healthcare.

Globalization has had additional side effects with epidemiological consequences. Massive migrations have increased the number of displaced and marginalized people who suffer from chronic infectious diseases without having access to proper medical care [Dwyer, 2004]. Migrants who live in camps and are in permanent danger of being evicted or deported, have hardly any prospects of acquiring citizen status, a prerequisite to effective claims of even the most basic human rights. Illegal immigrations bring with them diseases unknown in the host countries, causing hard to manage emergent and resurgent infectious conditions.

A little attended consequence of globalization is brain-drain of healthcare professionals. Trained in a poor country, nurses and doctors are tempted to take jobs in well paid developed nations, leaving their home-population under-staffed and unable to provide basic medical services. Professional migration is stimulated by richer nations that show no qualms in profiting from the educational efforts of poor countries, thus contributing to inequities in healthcare and disregarding their official utterances in favor of global social justice [Dwyer, 2007; Daniels, 2008].

Travel facilities have enhanced tourism and created a new side-line for those seeking medical services abroad. Rising costs are motivating people to explore healthcare facilities in less developed countries, creating an increasing flow of medical tourists, who are attended by qualified professionals and received in luxurious clinics set up in Third World countries that divert resources and man-power from their local public healthcare in order to serve the demands of the traveling patient, making huge profits that remain in the private realm. Local personnel, qualified professionals and resources are sequestered to serve in private facilities, thereby draining the already meager healthcare available to the non-paying indigenous population.

\section{The strategies of public health}

Public health policies and healthcare programs are mainly inspired by the values of four strategic guide-lines: responsibility, prevention, precaution, and protection, each approach inspired by a different perspective. Although traditionally evaluated in technical terms, there is a growing interest and need to study the ethical justifications and possible limitations of policies that have considerable impact on the well-being of communities and the life of its members, and submit them to public accountability. 
FOUR STRATEGIES OF PUBLIC HEALTH INTERVENTIONS

$\begin{array}{ll}\text { Strategic concept } & \text { Main theme } \\ \text { Responsability } & \text { causality } \\ \text { Prevention } & \text { efficacy } \\ \text { Precaution } & \text { opportunity } \\ \text { Protection } & \text { empowerment }\end{array}$

\subsection{Responsibility}

Responsibility is the ethical requirement to justify acts, actions or omissions; it differs from accountability in that it goes beyond merely giving account, actually making amends for having caused negative consequences. Accountability is a substantial part of responsibility focused on evaluating resources employed, programs fulfilled and errors committed. The ethical dimensions of responsibility are interwoven with public health in many ways. Search for causes of disease or of failing health is a responsible way of understanding processes, but it also has served to assign blame to the purported causal agent. Responsibility is intrinsic to public health activities performed with serious commitment to efficacy and excellence, and expected to meet the needs of those in distress. From the vantage point of public health, responsibility may be assigned to actions or omissions that cause or facilitate diseases, as well as for instituting preventive healthcare measures, or failing to do so. Thus, public health, being in charge of hygiene and public sanitation, is responsible for its effective procurement, but must also account for and repair failures or undesirable effects [Weed \& McKeown, 2003].

When an epidemic is announced, public health institutions are responsible for taking timely and technically appropriate measures to protect the population at risk, by designing and carrying out necessary immunization programs and defence strategies. This responsibility for action is compounded with the obligation to ensure that the measures undertaken are proven to be the best in existence. Failing to intervene, or spending public resources on deficient techniques or polemic goals are examples of responsibilities that must be faced in form of explanation and eventual repair.

Public health responsibilities include socially relevant epidemiological research, and commitment to gain and apply pertinent knowledge to the benefit of society [Weed \& McKeown, 2003]. Implicit in this agenda is the much discussed notion that public health ought to engage in active advocacy by shaping activities and setting goals for the sake of the common weal [Krieger, 1999]. These seemingly obvious ethical requirements need to be stressed in view of unfortunate episodes of abuse - eugenic programs, unethical research in Tuskegee Valley and Willowbrook, an ill-advised pandemic alert in 2009-.

As anticipated, the new approach to public health problems has shifted responsibilities by developing the credo of individual self-responsibility in preventing disease and engaging in safe conducts and health promoting life-styles. Reductions of the social element in public health increases healthcare inequities within societies and across nations, as self-care is being negotiated in the medical market rather than in the weakened realm of social security. Scholars reflecting on the reality of less developed countries have voiced their concern that political and economic forces urging individual self-responsibility in healthcare have the intended effect of blunting governmental responsibilities and diluting resources of public health budgets. Implicit in this restructuring is a complex and consequential shift from 
moral responsibility to economic and legal liabilities, creating litigious situations that consume human efforts and material resources in an infertile endeavour that worsens the reality and options of the underprivileged.

\subsection{Prevention}

Effective prevention obtains when risks are well defined and can be reduced or eliminated by methods proven to be efficient and sustainable, that is, finding a reasonable and acceptable balance between risk aversion, and negative effects (including costs). Ethical aspects require preventive actions to be indiscriminately available to all those in need of them. From being the defining goal of public health, prevention has been redirected into what came to be known as "Preventive Medicine", referred to "those activities that are in direct responsibility of the individual in the prevention of diseases and the protection of health [Smillie, 1947 as cited in Arouca, 2003]. Preventive medicine advocates have explicitly stressed that preventing disease "should be performed by the medical profession and not through any form of State Medicine" [Fishbein, 1947 as cited in Arouca, 2003]. Thus, much of prevention is deflected from public health policies and incorporated into clinical medicine, therefore addressing individuals rather than populations.

Public health traditionally engages in primary prevention targeted at avoidance of disease. Prevention becomes secondary and tertiary as it mingles with diagnosis and therapy, encouraging self-care and physicians' commitment to pursue disease prevention as part of their clinical practice. The medicalization of prevention leads to periodic and extensive diagnostic explorations in search of predisposing traits of incipient disorders, often resorting to routine prophylactic medication of the healthy. Recently, the term "quaternary prevention" is being employed to sift medical interventions through an ethics filter, and avoid the ill-effects of overmedication. Besides the prevention of iatrogenic effects, some authors suggest that rehabilitation and restoration of function should be the aim of quaternary prevention [Starfield et al, 2008]. The reassignment of many, though not all, preventive measures to prophylactic individual exploration and medication is symptomatic of a major shift from public health to clinical disease, causing the brunt of prevention to be absorbed by private healthcare organizations and practitioners.

Preventive actions are meant to avert risks and threats to the health of populations. Such actions are required to be effective, avoid unjustifiable and unnecessary interference with the private life of citizens, and target prevalent health problems rather than solely concentrating on individual high relative risk factors. Population-based prevention bases action on collective rather than individual risks. When preventive medicine is carried out as a clinical activity, the destitute in countries with limited resources will rarely get the benefit of preventive measures that have ceased to be governmental responsibility and been taken over by private institutions and healthcare professionals.

\subsection{Precaution}

A precautionary ethical principle was enounced in the early 1980s as a form of reconciling public acceptance of industrial activities, innovative products, and prevalent technical and extractive processes with their environmental and social impact [Godard, 2001]. Precaution is a decision-rule to be considered in the absence of scientific certitudes about potential consequences of risky situations and processes [Kriebel \& Tickner, 2001]. When harmful or irreversible risks to population health actually appear or are strongly suspected, effective 
and proportionate measures should not be postponed on grounds that scientific and technical knowledge is deemed uncertain or absent. Precaution mandates that whenever harmful risks are suspected but insufficiently defined, action should not be delayed, either to curtail existing situations and activities -post-damage formulation-, or to oppose, eventually postpone, suspicious innovative propositions requiring "safeguarding against serious and, particularly irreversible damage" [COMEST, 2005]. The broad essence of the "precautionary principle is that an action should not be taken when there is scientific uncertainty about its potential impact" [Goldstein, 2001], but critics have rejected such a prematurely sweeping approach because it would inhibit scientific progress and discourage technical innovations [Harris, 2007].

In a climate of uncertainty, precaution means negotiating risks and benefits between proponents of an activity that is under suspicion of being deleterious, and public opinion soliciting regulatory measures aimed at avoiding possible ill-effects. Inasmuch as it is a negotiation in uncertainty, the outcome will often depend on the rhetoric and political force of contending parties. In environmental issues, where little understood variables are the rule and precautionary attitudes are frequently invoked, vested interests will often prevail over civil society's reticence and public health's arguments. Precaution has proven a weak instrument in the hands of social forces unable to curtail the introduction of genetically modified crops and food, technologic sophistications that unleash global warming, or practices that pollute the environment and deplete natural resources.

When judicial conflicts ensue and resort to precautionary arguments, court decisions become unpredictable, for judges may have very different appraisals of risks and uncertainty. The suggested response is to reduce uncertainties, but as knowledge increases precaution should be superseded by well grounded prevention based on precise quantitative risk assessment.

Simplified views on the precautionary principle neglect two important elements: a) Precautionary assessment should involve civil society in order to broaden evaluative criteria; b) Precautionary strategies and the need for robust institutional surveillance require unbiased and uninfluenced politics in order to dictate fair and reasonable regulations and laws.

To apply the precautionary principle with sufficient force to oppose particular interests and devious influence requires control mechanisms capable of collecting and evaluating hard data, advancing a decision-making process based on all eventually available information, and recognizing the major social problems involved [Callon, Lascoumes \& Barthe, 2001]. Equally important is the surveillance of public health decisions taken in uncertainty, in order to detect any unwanted effects due to changes in policies inspired by precautionary arguments [Goldstein, 2001].

Excessive precaution and protracted inactivity, it is argued, may stifle progress, just as hasty dismissal of precautionary measures may precipitate disaster, thus warning that precaution is a flexible ethical stance, easily influenced by powerful vested interests, and susceptible to erroneous appraisals. The precautionary principle should also be recursively directed at itself, avoiding its overuse when evidence is clear, certain, and sufficient to inform decisions. Equally, precaution will be inappropriately applied when "there is no reasonable evidence to suspect a risk to public health." [Kriebel \& Tickner, 2001].

The 2008 pandemic panic was unleashed by major uncertainties as to the spreading potential of H1N1 virus, and the severity of the infection. WHO was deceitfully misinformed by experts committed to conflicting interests, health officials being erroneously 
led to recommend massive precautionary measures that depleted public health resources and resulted in huge profits for vaccine producing companies. Pharmaceutical products introduced in the market under the safeguard of precaution have caused severe, even lethal harm, requiring these drugs to be recalled, the thalidomide affair being one of the most dramatic instances: about 25000 children born with atrophic or absent limbs due to a new anti-anxiety drug prescribed to pregnant women. Considering the political weakness of public health institutions and the poor record of precautionary arguments in controlling environmental problems, it seems risky and unreliably to put too much stake on this ethical principle [Marchant, 2003].

In sum, the reliability of the precautionary principle depends on the honesty, good will and ethical solvency of all involved, in the hope that they will be loyal to the maxim of protecting the common weal, and avoid the perils of unknown but potentially deleterious or unwanted effects, as well as the temptations of quick profits obtained without sufficient safeguards.

\subsection{Protection}

Weary of State intervention, liberal and libertarian political nevertheless agree that even the most minimal State must preserve a solid protective policy towards its citizens and the national territory [Hobbes, 1978; Nozick, 1974]. In addition, the State is responsible for organizing undertakings that will reduce the impact of catastrophic natural events, and defend the population against massive threats -epidemics, scarcity of essential goods, pollution, environmental disasters -.

Protection is needed by those unable to obtain the basic goods required to survive and develop the capabilities that will empower them to plan a meaningful and socially integrated life [Sen, 1995]. The duty to provide essential goods needed for survival are considered to be primary, that is, they are to be served even if no correlative rights are claimed. Although socially recognized rights ought to be secured by correlative obligations, history shows that rights-language is too weak to ensure fulfilment, suggesting that it is more effective to directly demand the execution of essential and uncontroversial obligations. Those in power are under the moral obligation of protecting the weak, the destitute, the damaged and the vulnerable, insofar as they cannot fend for themselves [O'Neill, 1998]. Setting obligations is the correlate of respecting rights, with the advantage that it is a more binding and transparent presentation of what is morally due to human beings. Briefly, the obligation to protect the weak and defenceless can be directly appealed to without the need to proclaim the correlative basic rights, suggesting that talk about a right to health should be replaced with a governmental obligation to provide sanitary and medical protection to the population, at the very least covering the basic needs of the destitute.

In public health, social protection is the counterpart of self-care, invoked by those who admit that healthcare needs ought to be provided to the insolvent, marginalized and otherwise unable to access essential goods and services. Most Latin American Constitutions explicitly concede a right to health, to healthcare or to health protection, to be satisfied through environmental and public health policies, and medical-care services. More broadly, populations are to be protected by reducing the ill-effects of social and economic determinants causing inequities and extreme poor/rich divides, in other words, by aiming to lower the Gini index that measures income disparities, in order to reduce their impact on health inequities. Protection is at the base of a right to healthcare, preferably formulated as the State's obligation to provide indispensable but individually unattainable primary goods 
and basic services. The final goal of social ethics will always go beyond the elimination of life-threatening inequities, but hoping for the utopia of attaining global fairness will not feed, heal and educate the poor, who are in dire need of protection.

In a world where the privileged and the economically solvent are minority, States must honour the obligation to provide the basic needs human beings require to survive and function. Duties "are never generated in a vacuum: the idea of needs, and of entitlements based upon needs, always enters in to inform us why the duty is a duty, and why it matters" - [Nussbaum, 2006]. Basic needs are also expressed as lack of the basic capabilities required to survive and project a meaningful life as an integrated member of society. [Sen, 2000]. It is a matter of social justice that the disempowered be protected and assisted by social institutions that specifically address the unattended basic needs of the deprived. Consequently, the essential medical needs of the disempowered become a primary target of social healthcare arrangements, this being another way of calling upon public health to provide basic medical services to the needy who are unable to take care of themselves: "Protection from injury in the face of...ubiquitous and foreseeable vulnerabilities of the human condition is in large measure the task of justice." [O'Neill, 1998]

\section{Some special issues}

\subsection{Infectious diseases}

An introductory chapter on public health bioethics can hardly cover all pertinent subjects, so in this fourth part, a few topics have been selected in view of their actuality and importance. Infectious diseases have historically always been in the limelight of public health. New challenges require a reappraisal of well-established ethical norms now facing unprecedented debates and issues that cut across a wide-ranging agenda of public health problems including poverty, global justice, research strategies, public policies, individual responsibility. In recent decades, the emergence and resurgence of treatment resistant infections in affluent societies are again attracting the attention and preoccupation of health officials. Epidemiology is confronted with new and drug-resistant infectious agents, as well as unexpected forms of transmission, to the point where some experts are speaking of a new health transition triggered by the association of infectious and non-communicable diseases [Beaglehole \& Bonita, 1997].

Bioethics seems to have neglected a thorough debate on the ethics related to infectious diseases, preferring to delve in the more eye-catching problems of abortion, euthanasia, molecular biology and, more recently, neuroethics and nanoethics [Selgelid, 2005]. The $\mathrm{HIV} / \mathrm{AIDS}$ scourge, the increasing incidence of drug-resistant tuberculosis, and the unabated force of endemic diseases such as malaria and dengue, are bringing to light a complex array of ethical problems related to their unpredictable epidemiological behaviour.

Bioethics has been criticized for preferably delving in topics related to sophisticated scientific and technological developments, to the detriment of significant problems posed by infections. In their quest for novelty and originality, scholars have failed to take note that industrial development and technological impacts on the environment are changing the landscape of diseases caused by microorganisms and transmitted by unexpectedly aggressive vectors -urbanized rodents, insecticide-resistant arthropods, historically harmless bacteria turned virulent-. 
The tension between the communitarian goals of public health and individual autonomy shows peculiarities of its own in the area of infections, considering that each person may become a victim and a vector of infectious diseases. Individuals are called upon to cooperate and behave in a disciplined fashion, as is habitual in most public health policies. As a potential source of contagion, individuals have to protect themselves, as well as behave in such a way as not to infect others nor facilitate the spread of an epidemic bout [Battin et al, 2008]. The responsibility of combating modern infections is shared between public health efforts and individual discipline, not forgetting that clinical medicine must account for the way it employs antibiotics, and is expected to avoid the proliferation of resistant microorganisms, without neglecting fair and cost-conscious prescriptions.

The ethics of public health in dealing with infectious diseases must rely on some kind of regulations and impositions. A drug-resistant $\mathrm{TBC}$ infection may require isolation of affected patients, just as $\mathrm{VIH}(+)$ individuals are mandated to inform their condition to sexual partners and to their health caretakers. Ethics related to infectious diseases face problems induced by migration and the permeability of transnational borders to microorganisms unknown in host countries. The strong interdependence of poverty and susceptibility to infecting and transmitting agents needs to be taken into account in research and in eradication campaigns. Pharmaceutical industries' financial interest will often collide with the accessibility to medication and immunization in poor and distant regions. Biomedical research has systematically neglected the search for affordable vaccines against endemic diseases like malaria, and privately sponsored trials consistently support the 90:10 divide by preferably investing in marketable and profitable products. Not all infectious diseases are neglected. AIDS research has been lavishly funded and intensively pursued, no doubt because it is a very vivid threat to the well-being of the affluent.

More than other bioethics issues, infectious disease is intertwined with moral and religious considerations. Sexually transmitted diseases are related to promiscuity and unsafe sex; AIDS was initially believed to be a condition confined to homosexuals at a time when being gay was socially unacceptable and the Vatican made it publicly known that homosexual relations were sinful. Condoms were repeatedly rejected by the Catholic Church in Third World countries, under the predicament that they favoured casual sex, and public health was hampered in its efforts to control AIDS when the Church insisted that only abstinence is an adequate and morally acceptable protection.

\subsection{Healthcare promotion}

Health promotion is about convincing people to modify or adapt their habits and lifestyles in order to live healthy and disease free lives. Its basic tenet relies on stressing care and placing it at the same level of importance as cure. The explicit target of public health is to reduce population at risk, that is, the group or segment of the whole "which is making the greatest adverse contribution to the average" of a certain risk factor. The Canadian public approach has been to define a "Health Field Concept" that comprises four categories: human biology, environment, lifestyle, healthcare organization [Lalonde, 1981]. Such a very comprehensive public health strategy presents four caveats: First, sufficient resources should have secured adequate medical care services based on equal access; second, research ought to avoid excessive concentration on human biology -molecular epidemiology-, to the detriment of the other components of the health field concept; third, science has presented 
scanty and contradictory evidence concerning the causal impact of life-style factor, so that arguments intended to influence the public have not been convincing enough to significantly modify attitudes and habits; fourth, life-styles are negatively influenced by social determinants -urban stress, industrial pollution-, and by lavish and attractive campaigns to indulge in those habits that have been identified as health risks -alcohol consumption, fast cars, adventurous sports-. Health promotion faces complex situations that make observers wary whether resources are being judiciously and reasonably diverted from more pressing medical needs.

Public health will resort to promotional campaigns whenever it detects a health problem but sees no clear-cut way of solving it. Promoting healthcare has come to the forefront of medicine based on the prevalence of chronic, non-communicable diseases, the influence of risk factor epidemiology plagued by causal uncertainties, and the new public health's insistence on self-care. Disapproval ranges from behaviour patterns that people enjoy, to habits and practices they are unable to curtail, leading to disparate views on what wellbeing is about -exercise versus sedentary habits, diets versus gourmandising, abstinence versus indulging in recreational substances-. Especially in less affluent societies, health recommendations may be too onerous for the poor to follow.

Health promoting recommendations may reasonably revert to mandatory regulations when their effectiveness is proven beyond reasonable doubts, as in the mandatory use of seatbelts, alcohol-free driving, curtailment of passive smoking, vaccination as travel requirement. Unless it can be proven that certain practices are deleterious to others, or will adversely influence a public good, indications for healthy comportment remain bland and irregularly headed.

The effectiveness of promotional campaigns is anybody's guess. Social alcohol consumption may have harmful effects, but will hardly be influenced by deterrent campaigns. On the other hand, fads and fanaticism may be unleashed by persistent propaganda, and a state of protracted public panic may follow alarming official warnings or awesome media displays. Negative and uncertain consequences of promotional campaigns should be considered when planning allocation of scarce resources that will become unavailable for less spectacular but perhaps more basic healthcare needs.

\subsection{Public health in war and bioterrorism}

Armed conflicts have been an attractive intellectual turf for philosophy, especially in view of the $20^{\text {th }}$ century's infamous record of two World Wars, ferocious regional conflicts, genocide, guerrilla warfare, and terrorism. Inevitably, bioethics has been involved in these matters, producing a considerable amount of literature where philosophical and ethical arguments are often polluted with military, political, doctrinal and other contingent considerations, thus stimulating harsh ideological discussions - "there is a rough symmetry between the underlying principles of contemporary just war and bioethics" [Gross, 2004]-, rather than deliberation and reasoned approaches.

The ethical reflection on armed conflicts revolves around the concepts of just war and the justification of acts of public violence. The doctrine of just war -jus ad bellum-accepts two circumstances as giving moral support to engage in armed hostilities in foreign territories: retaliation, and defending basic humanitarian principles that are being violated by rogue states. As for acceptable methods of warfare -jus in bello-, they explicitly disallow harming civilians and civilian targets, and engaging in exceptionally damaging aggressions such as 
biological and chemical arms. Torture has been condemned and prohibited, but unsettling allowances are made under the "ticking bomb" allegation, which purports the urgency of extracting information in order to avert major disasters [Lee, 2007].

The reason for bringing up these issues in a text on public health bioethics dates back to the 2002 terrorist attacks on New York. At that point, when terrorism threatened to be violating all restraints, fear of exacerbated bioterrorism was kindled by a few attempts at posting envelops with anthrax spores, leading officials and the media to engage public health in comprehensive programs including strategic preventive planning in the event of a terrorist induced epidemic, setting up emergency vaccination programs, as well as developing biological defensive and retaliatory weapons. The U.S. government responded with a huge allocation of resources to public health, alas $4 / 5^{\text {th }}$ of which were earmarked for antibioterrorism research, the rest to support the precarious finances of routine public health programs.

Confident that public health had the expertise to deal with biological threats, the U.S. government called upon law scholars, officials and other experts to develop a Model State Emergency Health Power Act commissioned to design appropriate measures in case of catastrophic public health emergencies. Vaccination programs in strategic areas and for persons posing risks of massive contagion would be mandatory if needed; health officials would be empowered to regulate the distribution and pricing of scarce medical supplies, eventually compelling healthcare workers to remain on duty against their will [Hodge \& Gostin, 2004]. Some scholars voiced their concern at the prospect of over-reactive precedents being set [Bayer \& Colgrove, 2004], pointing out the perils of upsetting the delicate balance between individual rights and restrictive policies in order to secure protection of the public.

Many questions remained unanswered, anticipating havoc should bioterrorist emergencies occur in the future: ought chronically scarce public health resources to be used in research and policies concerned with biological terrorism? Who will set priorities in an emergency: military strategists or public health experts? How serious and imminent must a threat or an actual attack be to curtail rights and declare a state of emergency? Who will decide what commensurate and appropriate countermeasures to undertake?

In the final analysis, public health bioethics must feel unhappy when pragmatic and contingent arguments are employed to neglect and violate cherished moral standards and hard-won rights. Equally unsettling is the prospect that bioethics must be compelled to abide by the decisions of those in power when declaring a just war and allowing the arbitrary toleration of flagrantly abusive jus in bello practices - Guantánamo, Abu Ghraib-. Even though public health activities have historically been required to serve as the practical arm of political goals in form of medical police or biopolitics, current efforts at employing public health know-how for military purposes is a development that goes beyond what rational bioethics ought to justify.

\section{Outlook}

As for the future of public health, there is little information to allow educated guesses, and prognosis is mostly made from the vantage point of hopes and wishful thinking. Most people agree that health should be a right, to be universally claimed and honoured, which means including the marginalized, the poor, and the distant. But theory alone rarely transcends social realities, political vagaries, and economic pressures. Risk-factor 
epidemiology with its emphasis on the individual ought to be subordinated to population studies, focusing on socioeconomic and environmental conditions that need to be modified for the benefit of human health. The world is already enmeshed in deleterious influences on human populations' health and survival conditions, requiring that present needs and interests be accounted for without neglecting the anticipated needs of future generations. Nevertheless, if resources are scarce, the future ought to be discounted in order to attend the pressing needs of the now living.

Propositions in ethics have a natural tendency to strongly collide with actual practices and trends. Risk factor epidemiology and the new public health are hostile to State protected human rights and deaf to healthcare as an obligation due to all and everyone. Marketoriented neoliberalism has little patience with strong, centrally planned and financed public health programs, and science prefers reductionist approaches and seductive technological developments, instead of searching for measures to solve grass-roots problems [Pearce, 1996]. These are widely differing and incompatible viewpoints, proving that bioethics in public health faces arduous work in deliberating these issues and enhancing a fundamental ethics protecting the common weal as widely and extensively as necessary. Public health is in permanent danger of becoming a puppet discipline of political forces and ideologies, unless it develops its own brand of applied bioethics engaged in exploring values and preferences that ought to inspire public health-related policies. This query will depend on fundamental political outlooks and reflection at the philosophical level, either understanding social factors as powerful forces capable of modelling and manipulating its citizens, or seeing human beings as individuals who freely structure their actions and their relations in a climate of secure social equity.

\section{A wistful epilogue}

History teaches that neither political power nor scientific discoveries triggering technical developments are the driving forces of public health. In fact, they seem to follow diverging pragmatic goals, often forgetting or unwilling to raise the question who the beneficiaries of these goals are or ought to be. Civilization and progress are no guarantees for a robust public health; quite to the contrary, material well-being leads neoliberal politics to neglect the public sphere and reduce the common weal to law and order. Much of public health's activities have been dictated by needs of the moment, above all catering to predominant vested interest. Reacting to emergencies or to pressing need is but one of public health's tasks, but a more fundamental question is its place in improving health standards and helping avoid diseases that can be eradicated, as well as mitigating such derangements as can be substantially reduced in their toll of suffering, poverty, disempowerment and premature death.

There are too many differing proposals to suggest that public health has found its way or is on the right path. There is little agreement about such basic concepts as health, disease, social commitment to primary prevention by central institutions, the need for publicly supported medical care, and the pursuance of relevant knowledge for meaningful and efficient health promotion. Should we understand health as well-being or as absence of disease? Shall disease be considered a predisposition, an overt derangement of the organism, a poor adaption to social and environmental conditions? Research in epidemiology wavers between molecular studies and analysis of social and economic 
contexts, because it remains an unsettled question whether health is better served by improving the world we live in, or seeking to increase individual defences and protection against external harshness that prevails beyond repair. These alternatives also trouble ecologists, illustrating how public health and the environment are intertwined in a common quest to better the human condition by making it less vulnerable and better adapted to thrive in the world it inhabits.

The obvious but self-defeating answer seems to be eclecticism served by interdisciplinary approaches, multicausal and multilevel explanations, and global proposals. Delaying pragmatic approaches while academia continues to delve in freely associative theorizing that eludes the knotty problems of reality, seems severely inadequate if we admit that by any standard or parameter, the human population is worse off than ever before: more poverty, hunger and endemic disease, increasing inequality in terms of material goods, and inequity in terms of justice. The environment is becoming unfriendly and future prospects are not promising.

Poverty and destitution affects billions of people. It has become standard procedure to introduce discussions on the woes of the world, by throwing in some impressive statistics about disease prevalence, hunger, poverty, and other dire deprivations. Such rhetoric should be employed sparingly, for it tends to anesthetize public opinion. The recognition of suffering is not a quantitative matter, it is more a question of emotional distress, moral uneasiness, and actual commitment. One might apply to statistics what S. Sontag wrote about the emotional dulling when permanently confronted with images of horror and suffering: "Shock can become familiar. As one can become habituated to horror in real life, one can become habituated to the horror of certain images." [Sontag, 2003]. If lively images can dull the senses, how much easier it is to become indifferent to sheer statistics that obscure the suffering of actual human beings.

Lamentations are usually followed by well-meant but unsubstantiated proposals that are too distant from Realpolitik -the realities of politics in a world dominated by economic reasoning-, to make any difference. Impotence fires the imagination, not always in a positive way: some voices consider that status quo conditions will lead to a Darwinian selection where the poor will not survive while the affluent make true their hopes of enhancement and post-human development. Dissent and concern must step down from the ivory tower and become involved in ample participative deliberation that emphasizes how moral legitimacy ought to precede legislation and political engagement.

There have been a few publications specifically addressing the "Philosophical basis for public health", that are exploring the field and coming up with some tentative suggestions to initiate a daunting task [Weed, 1999]. Bioethics in public health is called upon to deliberate in depth with the aim of emerging with reasonable proposals.

\section{References}

Almeida, C. (2002). Equidade e reforma sectorial na América Latina: um debate necessário. Cadernos Saúde Pública 18 (Supl), pp. (23-36)

Arouca, S. (2003). O dilemma preventivista, Editora UNESP-Editora FIOCRUZ, ISBN 8572129-507-1, São Paulo - Rio de Janeiro. 
Arras, J.D., Fenton E.M. (2009). Bioethics \& human rights. Hastings Center Report, 39, pp. (1738).

Battin, M. P, Smith, C.B., Francis, L.P., Jacobson, J.A. (2008). Towards control of infectious diseases: Ethical challenges for a global effort. In: International public health policy and ethics. Boylan, M. (ed.), pp. (191-214), Springer, ISBN 978-1-4020-8616-8, Dordrecht

Bayer, R., Colgrove J. (2004). Rights and dangers: bioterrorism and the ideologies of public health. In: In the wake of terror. Moreno, J.D. (ed.), pp. (51-74), The MIT Press, ISBN 0-262-63302-7, Cambridge London

Beauchamp, D.E., Steinbock, B. (1999). New ethics for the public's health, Oxford University Press, ISBN 0-19-512439-1, New York Oxford

Beauchamp, TL., Childress, JF. (2001). Principles of biomedical ethics. $5^{\text {th }}$ ed. Oxford University Press, ISBN 0-19-514332-9, Oxford New York

Beaglehole, R. , Bonita, R. (1997). Public health at the crossroads, Cambridge University Press, ISBN 052158665 8, Cambridge

Boylan, M. (2008). Introduction: international public health: morality, politics,poverty, war, disease. In: International public health policy and ethics, Boylan M. (ed.), pp. (1-12), Springer, ISBN 978-1-4020-8616-8, Dordrecht

Callon, M., Lascoumes, P., \& Barthe, Y. (2001). Agir dans un monde incertain, Edition du Seuil, ISBN 978-2-02-040432-7, Paris

Caplan, A.L., Engelhardt Jr., H.T., \& McCartney, J.J. (1981). Concepts of health and disease. Addison-Wesley Publishing Company, ISBN 0-201-00973-0-, Reading Mass.

Carrol, P.E. (2002). Medical police and the history of public health. Medical History 46, (461494)

COMEST. (2005). The precautionary principle, UNESCO, Paris.

Cunnigham, A., Grell, O.P. (2000).The four horsemen of the Apocalypse, Cambridge University Press 2000. ISBN 0-521-46701-2, Cambridge UK

Daniels, N. (2006). Equity and population health: towards a broader bioethics agenda. Hastings Center Report 36, (22-35)

Daniels, N. (2008). International health inequalities and global justice. In: International public health policy and ethics, Boylan M. (ed.), pp. (109-129), Springer, ISBN 978-1-40208616-8, Dordrecht

Defoe, D. (1722) A journal of the plague year. Matsumoto T, Widger D. (Prod.) (2006). http:/ / www.gutenberg.org Accessed Nov. 14, 2010

Dwyer, J. (2004). Illegal immigrants, healthcare, and social responsibility, Hastings Center Report, 34, pp. (34-41)

Dwyer, J. (2007). What's wrong with the global migration of healthcare professionals? Individual rights and international justice, Hastings Center Report 37 (36-43)

Fayerweather, W.E., Higginson, J., Beauchamp, T.L. (eds.) (1991). Ethics in epidemiology. Journal of Clinical Epidemiology 44, Supp. I, (1S-170S)

Fraser N. Scales of justice. (2009). Columbia University Press, ISBN 978-0-231-14680-7, New York

Goddard O. (2001). Principe de Précaution. In: Nouvelle encyclopédie de bioéthique, Hottois G, Missa J-N. (eds.), pp. (650-658), De Boeck Université, ISBN 2-8041-3712-0, Bruxelles 
Goldstein, B.D. (2001). The precautionary principle also applied to public health actions. American Journal of Public Health, 91, 9, pp. (1358-1361)

Gordon, J.S. (2008). Poverty, human rights, and just distribution. In: International public health policy and ethics, Boylan, M. (ed.), , pp. (131-141), Springer, ISBN 978-1-4020-8616-8, Dordrecht

Gostin, L. (2002). Public health law, ethics, and human rights: mapping the issues. In: Public Health law and ethics: a reader, Gostin L (ed.), University of California Press: 1-19. ISBN 0-520-23174-9, Berkeley Los AngelesThe Milbank Quarterly, 88, pp. (149-168)

Gross, M. (2004). Bioethics and armed conflict, The MIT Press, ISBN 0-262-57226-5-, Cambridge London

Hedgecoe, A.M. (2004). Critical bioethics: science critique of applied ethics. Bioethics, 18, pp. $(102-143)$

Harris, J. (2007). Enhancing evolution, Princeton University Press, ISBN 978-0-691-12844, Princeton Oxford

Hessler, K. (2008). Exploring the philosophical foundations of the human rights approach to international public health ethics. In: International public health policy and ethics, Boylan M. (ed.), pp. (31-43), Springer, ISBN 978-1-4020-8616-8, Dordrecht

Hobbes, T. (1978). Leviathan (1651), Collins/Fontana, ISBN 000633066 5, Glasgow

Hodge Jr., J.G., Gostin, L.O. ( 2004). Protecting the public's health in an era of bioterrorism: the Model State Emergency Health Power Act. In: In the wake of terror, Moreno JD. (ed.), pp. (17-32) The MIT Press, ISBN 0-262-63302-7, Cambridge London

Illies, C. (2008) Why should we help the poor? Philosophy and poverty. In: International public health policy and ethics, Boylan M. (ed.), pp. (143-156), Springer, ISBN 978-14020-8616-8, Dordrecht

Kass, N.E. (2001). An ethics framework for public health. American Journal of Public Health 91, pp. (1776-1782)

Kriebel, D. \& Tickner, J. (2001). Reenergizing public health through precaution. American Journal of Public Health, 91, 9, pp. (1351-1355)

Krieger, N. (1999). Questioning epidemiology: objectivity, advocacy, and socially responsible science. American Journal of Public Health, 89, 8, pp. (1151-1153)

Lalonde M. (1981). A new perspective on the health of Canadians. Minister of Supply and Services Canada. ISBN 0-661-50019-9, Ottawa

Lee SP. (2007). Intervention, terrorism, and torture, Springer, ISBN 2-4020-4677-4, Dordrecht

Lloyd GER. (1978). Hippocratic writings. Harmondsworth, Penguin Books Ltd. ISBN 014 040.0311.

Macey D. (2009).Rethinking biopolitics, race and power in the wake of Foucault. Theory, Culture \& Society 6:186-205.

Mann JM. (1997). Medicine and Public Health. Ethics and Human Rights. Hastings Center Report 27, pp. (6-13)

Marchant GE. (2003). From general policy to legal rule: aspirations and limitations of the precautionary principle. Environmental Health Perspectives 14, pp. (17991803) 
Mechanic D. (1978). Medical sociology, The Free Press, ISBN 0-02-920720-7, New York Nozick R. (1974). Anarchy, state and utopia, Basic books ISBN 063119780 X, New York

Nussbaum, M. (2006). Frontiers of justice. Cambridge, The Belknap Press, ISBN 0-674-01917-2, London

O’Neill, O. (1998).Towards justice and virtue, Cambridge University Press. ISBN 052148099 2, Cambridge

Pearce, N. (1996). Traditional epidemiology, modern epidemiology, and public health, Amercian Journal Public Health 86, pp. (678-683)

Petersen, A., Lupton, D. (2000). The new public health. Sage Publications, ISBN 07619 5404, London

Petryna, A. (2007). Clinical trials offshored: on private sector science and public health. BioSocieties 2, pp. (21-40),London

Pogge, T.W. (2005). World poverty and human rights. Cambridge UK, Polity Press, ISBN 07456-2995-4-

Purdy, L. (2004). The politics of preventing premature death. In: Public health policy and ethics, Boylan M. (ed.), pp. (167-185), Kluwer Academic Publisher. ISBN 1-40201763-4, Dordrecht.

Purdy L. (2008). Exporting the "Culture of Life". In International public health policy and ethics, Boylan, M. (ed.), pp. (91-106), Springer: ISBN 978-1-4020-8616-8, Dordrecht

Quigley, M., Harris, J. (2008). Personal or public health? In: International public health policy and ethics, Boylan M. (ed.), pp. (15-29), Springer, ISBN 978-1-4020-8616-8, Dordrecht

Rothman D. (1991). Strangers at the bedside. Basic Books. ISBN 0-465-08210-6.

Rose, G. (1985). Sick individuals and sick population. International Journal of Epidemiology 14, pp. 32- 38.

Rosen, G. (1993). A history of public health. The Johns Hopkins University Press. ISBN 0-80184645-5, Baltimore

Selgelid, M.J. (2005). Ethics and infectious disease. Bioethics 2005;19:272-289.

Sen, A. (1995). Inequality reexamined. Harvard University Press. ISBN 0-674-45256-9, Cambridge Mass.

Sen, A. (2000). Development as freedom. New YoeK; Alfred A. Knopf. ISBN 0-375-40619-0.

Singer, P. (2004). Outsiders: our obligation to those beyond our borders. In: The ethics of assistance, Chatterjee D. (ed.), pp. (11-32), Cambridge University Press, ISBN 0521 52742 2, Cambridge UK

Sontag S. (2003). Regarding the pain of others. Picador, ISBN 0-312-42219-9, New York

Susser, M. (1998). Does risk factor epidemiology put epidemiology at risk? Peering into the future. Journal of Epidemiology \& Community Health 52, pp. (608-611)

Susser, M., Susser, E. (1996). Choosing a future for epidemiology: from black box to Chinese boxes and eco-epidemiology. American Journal Public Health 86, pp. (825-829)

Starfield, B., Hyde, Jj, \& Gervas, J., Heath I. (2008). The concept of prevention: a good idea gone astray. Journal of Epidemiology \& Community Health 62, pp. (580-583)

Touraine, A. (1985). An introduction to the study of social movements. Social Research 52, pp. (749-787) 
Van der Maesen, L.J.G., Nijhuis H.G.J. (2000). Continuing the debate on the philosophy of modern public health: social quality as a point of reference. Journal of Epidemiology $\mathcal{E}$ Community Health 54, (134-142)

Verweij, M., Dawson, A. (2007).The meaning of 'public' in 'public health'. In: Ethics, prevention and public health, Dawson, A., Verweij, M. (eds.). (2007). Oxford University Press, ISBN 978-0-19-929069-7, Oxford.

Victora, C.G., Habicht, J-P., \& Bryce, J. (2004). Evidence-based public health: Moving beyond randomized trials. American Journal of Public Health 94, pp. (400-405)

Weed, D.L. (1999). Towards a philosophy of public health. Journal of Epidemiology $\mathcal{E}$ Community Health 53, pp. (99-104)

Weed D.L. \&, McKeown,R.E. (2003). Science and social responsibility in public health. Environmental Health Perspectives, 111, 14, pp. (1804-1818) 


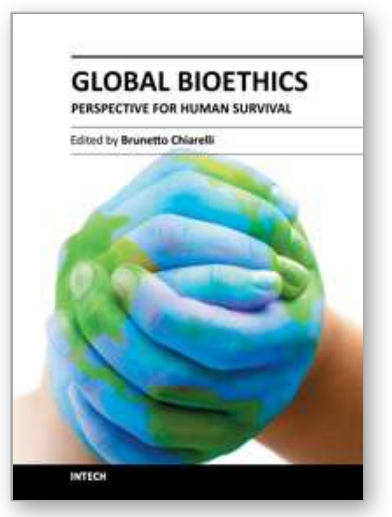

\author{
Global Bioethics - Perspective for Human Survival \\ Edited by Prof. Brunetto Chiarelli
}

ISBN 978-953-307-537-2

Hard cover, 152 pages

Publisher InTech

Published online 04, November, 2011

Published in print edition November, 2011

Two new factor have been added to the ideological change in the second half of the past century: the "ecological impact" of humankind on the environment due to the population increase; and the "innovative impact of science, first with atomic physics, which introduced the scission of the fundamental unit of matter, the atom, and then witch molecular biology, which led to the decoding of genetic information and intervention of biological engineering that annihilate our concepts of individual and species as fundamental units in biology. This stage of fundamental rethinking is however overshadowed by the threat of ecological disaster and catastrophic population increase, which not only impose limits to development, but undermine the very survival of Humankind. The future survival our species in fact depends on the interaction between its reproductive characteristics and the productivity of the territory, which, even if increased by the intellectual capability of the human brain, has intrinsically limits. The adaptive choices (which are also biotechnological and biomedical) of the interaction between human population and the natural ambience is the conceptual basis of the new discipline "Global Bioethics".

\title{
How to reference
}

In order to correctly reference this scholarly work, feel free to copy and paste the following:

Miguel Kottow (2011). Public Health Bioethics, Global Bioethics - Perspective for Human Survival, Prof. Brunetto Chiarelli (Ed.), ISBN: 978-953-307-537-2, InTech, Available from:

http://www.intechopen.com/books/global-bioethics-perspective-for-human-survival/public-health-bioethics

\section{INTECH}

open science | open minds

\section{InTech Europe}

University Campus STeP Ri

Slavka Krautzeka 83/A

51000 Rijeka, Croatia

Phone: +385 (51) 770447

Fax: +385 (51) 686166

www.intechopen.com

\section{InTech China}

Unit 405, Office Block, Hotel Equatorial Shanghai

No.65, Yan An Road (West), Shanghai, 200040, China

中国上海市延安西路65号上海国际贵都大饭店办公楼 405 单元

Phone: +86-21-62489820

Fax: $+86-21-62489821$ 
(C) 2011 The Author(s). Licensee IntechOpen. This is an open access article distributed under the terms of the Creative Commons Attribution 3.0 License, which permits unrestricted use, distribution, and reproduction in any medium, provided the original work is properly cited. 